\title{
Role of Lipotoxicity and Contribution of the Renin-Angiotensin System in the Development of Polycystic Ovary Syndrome
}

\author{
Alexandre Connolly $\mathbb{D}^{1,2}$ Samuel Leblanc, ${ }^{2}$ and Jean-Patrice Baillargeon $\mathbb{D}^{2}$ \\ ${ }^{1}$ Department of Pharmacology-Physiology, Faculty of Medicine and Health Sciences, 3001 12e Avenue Nord, \\ Université de Sherbrooke, Sherbrooke, QC, Canada J1H 5N4 \\ ${ }^{2}$ Division of Endocrinology, Department of Medicine, Faculty of Medicine and Health Sciences, 3001 12e Avenue Nord, \\ Université de Sherbrooke, Sherbrooke, QC, Canada J1H 5N4 \\ Correspondence should be addressed to Jean-Patrice Baillargeon; jp.baillargeon@usherbrooke.ca
}

Received 28 January 2018; Accepted 3 May 2018; Published 3 June 2018

Academic Editor: Dario Iafusco

Copyright (C) 2018 Alexandre Connolly et al. This is an open access article distributed under the Creative Commons Attribution License, which permits unrestricted use, distribution, and reproduction in any medium, provided the original work is properly cited.

\begin{abstract}
Polycystic ovary syndrome (PCOS) is a common and significant condition associated with hyperandrogenism, infertility, low quality of life, and metabolic comorbidities. One possible explanation of PCOS development is cellular dysfunction induced by nonesterified fatty acids (NEFAs), that is, lipotoxicity, which could explain both the hyperandrogenemia and insulin resistance that characterize women with PCOS. The literature suggests that androgen biosynthesis may be induced by overexposure of androgen-secreting tissues to NEFA and/or defective NEFA metabolism, leading to lipotoxic effects. Indeed, lipotoxicity could trigger androgenic hyperresponsiveness to insulin, LH, and ACTH. In most PCOS women, lipotoxicity also causes insulin resistance, inducing compensatory hyperinsulinemia, and may thus further increase hyperandrogenemia. Many approaches aimed at insulin sensitization also reduce lipotoxicity and have been shown to treat PCOS hyperandrogenemia. Furthermore, our group and others found that angiotensin II type 2 receptor (AT2R) activation is able to improve lipotoxicity. We provided evidence, using C21/M24, that AT2R activation improves adipocytes' size and insulin sensitivity in an insulin-resistant rat model, as well as androgen levels in a PCOS obese rat model. Taken together, these findings point toward the important role of lipotoxicity in PCOS development and of the RAS system as a new target for the treatment of PCOS.
\end{abstract}

\section{Introduction}

Polycystic ovary syndrome (PCOS) is a common condition affecting $6-8 \%$ of women of childbearing age [1]. It is the most frequent endocrine disorder among young women in North America. In addition to being the most frequent cause of female anovulatory infertility [2], PCOS is the commonest cause of hyperandrogenism in women [3], thus leading to esthetical concerns such as excessive hair growth, acne, and male-pattern alopecia. In addition, PCOS is currently considered a paradigm of cardiometabolic disease, since the prevalence of metabolic syndrome [4], dyslipidemia [5], and type 2 diabetes [6,7] is much higher in PCOS women than in normal age- and BMI-matched women. Indeed, PCOS women display metabolic insulin resistance and compensatory hyperinsulinemia [8], which play a critical role in the syndrome's development $[9,10]$. Insulin resistance is classically defined as the reduced ability of insulin to stimulate glucose disappearance in peripheral tissues as well as inhibit hepatic glucose production and adipose tissue lipolysis $[11,12]$, which corresponds to the main metabolic actions of insulin.

Lipotoxicity, referring to the cellular adverse consequences of nonesterified fatty acids (NEFAs), is widely studied for its implication in the development of dysfunctions in adipose tissue, muscle, and liver and in pancreatic $\beta$-cells $[13,14]$, leading to metabolic insulin resistance and type 2 diabetes. Lipotoxicity could also be implicated in PCOS pathophysiology, both through increased androgen production and through induction of systemic insulin resistance leading to hyperinsulinemia. Yet, many questions remain unanswered regarding the mechanisms by which metabolic 
insulin resistance and/or lipotoxicity leads to hyperandrogenemia and how this could be prevented or reversed.

To control the serious short- and long-term consequences of PCOS, it is becoming primordial to identify new therapeutic targets in the treatment of PCOS. To this day, the first line of treatment for infertility and hyperandrogenism in PCOS women is lifestyle management [15], which is difficult to maintain during the long term and probably ineffective in most normal-weight women. The main pharmacologic treatment recommended for PCOS, that is, hormonal contraception, is effective to control PCOS symptoms but not cardiometabolic risks, and other drugs, such as the insulin sensitizer metformin, are too weak to fully treat PCOS manifestations in most women. However, recent evidence suggests a potential benefit of type 2 angiotensin II (Ang II) receptor (AT2R) stimulation for improving both lipotoxicity and hyperandrogenism. Although we recognize that other important mechanisms and effective therapeutic approaches are of interest in PCOS, this review will focus on the role of lipotoxicity as an innovative hypothesis for PCOS development and of the AT2R pathway as a new target for the management of women with PCOS.

\section{Role of Lipotoxicity and Insulin Action in the Development of Polycystic Ovary Syndrome}

2.1. Insulin Actions and Metabolic Insulin Resistance. Despite variations caused by fasting and food intake, plasmatic glucose levels remain stable due to the metabolic actions of insulin on target tissues, such as increasing glucose uptake by muscles and adipose tissues and inhibiting glucose production in the liver [16]. Insulin mediates its actions through a tyrosine kinase receptor, which is a heterotetrameric protein formed of two extracellular alpha subunits and two transmembrane beta subunits. Once activated by insulin binding, the insulin receptor changes its conformation, which increases its beta subunit kinase activity, leading to phosphorylation of its intracellular substrates. Two major types of actions can then be mediated, as illustrated in the left part of Figure 1: metabolic and mitogenic actions. For metabolic actions, members of the insulin receptor substrate (IRS) family are phosphorylated by the insulin receptor, which are then recognized by effector molecules, such as PI3-K that triggers the recruitment of Akt, an important signal transduction molecule for glucose uptake, regulation, and metabolism. For mitogenic actions, such as cell growth and differentiation, insulin receptors phosphorylate Shc or IRS, enabling their association with Grb2 and SOS, resulting in Ras activation that initiates a cascade of phosphorylations leading to MAPK/ERK activation [16].

In pathologic situations like obesity, regulation of insulin signaling is altered by numerous internal and external stimuli, including nutrients like lipids, leading to metabolic insulin resistance [13] and other consequences (discussed below). In this situation, impaired glucose uptake in insulin-sensitive tissues and hepatic glucose production lead to an increase in insulin secretion in order to maintain normal glucose levels, that is, compensatory hyperinsulinemia. This is possible as long as pancreatic $\beta$-cells can secrete enough insulin to compensate. If not, glucose levels will rise to levels compatible with diabetes.

2.2. Insulin Resistance in Polycystic Ovary Syndrome. Defective action of insulin in PCOS women has been well described and confirmed in many studies since more than 25 years [8]. Insulin sensitivity in PCOS women is 35 to $40 \%$ lower than that in healthy women with similar BMI [17-19], such that most PCOS women display insulin resistance and compensatory hyperinsulinemia, which seem to play an important role in PCOS pathogenesis $[9,10]$. Using the gold standard method, the glucose-insulin clamp, to assess metabolic insulin resistance, many studies in different populations found that insulin sensitivity was significantly lower among obese and nonobese PCOS women in comparison to healthy women within the same obesity subgroup $[8,11,12,20]$. However, some studies in the subgroups of nonobese women found that insulin sensitivity was similar among women with or without PCOS $[21,22]$ or that the lower insulin sensitivity observed in PCOS women disappeared after correction for truncalabdominal fat distribution [23]. Furthermore, Ciampelli et al. discovered that lean PCOS women with normal insulin levels had completely normal insulin sensitivity [24]. In summary, among nonobese women with PCOS, some display insulin resistance that may be due to abdominal obesity and others are not more insulin resistant than the general population.

Altogether, these results suggest that insulin resistance and hyperinsulinemia certainly contribute to either unveiling or worsening of the syndrome in women predisposed to PCOS, but it may not be the actual cause of the predisposition to the syndrome, at least in some women with PCOS. Selection of women who have a more severe PCOS phenotype due to the contribution of insulin resistance and/or hyperinsulinemia would explain why studies usually found that PCOS women display lower insulin sensitivity than controls on average, even within BMI subgroups.

\subsection{Implication of Insulin Action in PCOS Hyperandrogenemia} Based on Clinical Studies. In vivo studies have shown that women with PCOS display both adrenal and ovarian androgenic hyperresponsiveness to $\mathrm{LH}[25,26]$ and ACTH $[27,28]$. Interestingly, many studies found that this exaggerated androgenic response was curbed after treatment improving metabolic insulin resistance in both lean and obese PCOS women [28-31], but not after chronic suppression of LH $[25,26]$ or ACTH $[32,33]$. These findings suggest that this hyperresponsiveness is not due to chronic LH or ACTH activation, but maybe caused by insulin resistance or related factors.

Regarding studies linking insulin and androgen production, Nestler et al. were among the first to show that insulin levels were directly related to androgen production in vivo [34]. They showed that reducing $\beta$-cell secretion of insulin in obese and hyperinsulinemic PCOS women with diazoxide, which reduces insulin secretion directly in pancreatic $\beta$-cells, lowered significantly free and total testosterone after only 10 days. A 6-month randomized control trial also demonstrated 


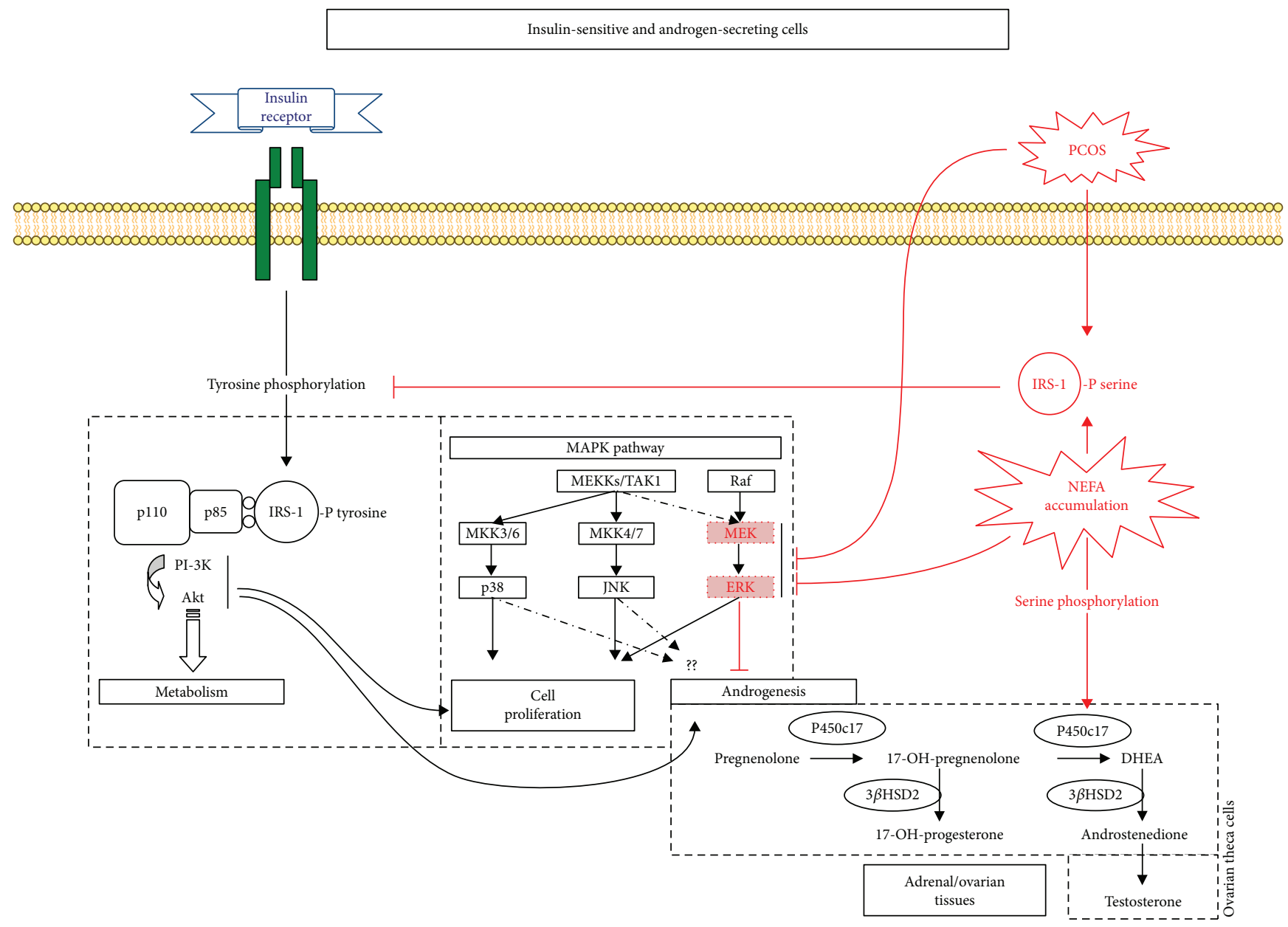

FIGURE 1: Proposed cellular mechanisms involved in insulin-stimulated androgen biosynthesis, PCOS-associated defects, and free fatty acidinduced insulin resistance and androgen production, together with AT2R and PPAR $\gamma$ actions. Serine phosphorylation of IRS-1 prevents its binding with PI3K and inhibits insulin signaling. Moreover, serine phosphorylation of P450c17 increases its 17,20-lyase activity and thus androgen biosynthesis. Interestingly, serine phosphorylation of IRS-1 is constitutively increased in PCOS women and increased by nonesterified fatty acid (NEFA) overload. Insulin-stimulated androgen production has been shown to be reduced by specific inhibition of PI3K and increased by specific inhibition of MEK. MEK/ERK activity was found to be constitutively reduced in PCOS women and inhibited by NEFAs. It was also suggested that P450c17 activity may be stimulated by other players of the MAPK pathway, such as MKK3/6-p38 and MKK4/7-JNK, whose activities are not reduced, and may be even increased, in women with PCOS. Adapted from [10].

that lowering postprandial insulin levels, using acarbose that slows down intestinal glucose absorption, significantly decreases the free androgen index among obese hyperinsulinemic PCOS women, in comparison to the placebo [35].

Moreover, we showed in lean normoinsulinemic PCOS women who were not insulin resistant based on a glucoseinsulin clamp that lowering their insulin secretion with diazoxide for 8 days was associated with a significant drop in their free testosterone and androstenedione levels [36]. Since their insulin levels were normal at the baseline, this study suggests that lean, insulin-sensitive women with PCOS display hyperresponsiveness to insulin, which could also be the case for all women with PCOS. Our group demonstrated as well that nonobese normoinsulinemic women with PCOS randomized to either metformin, rosiglitazone, or the combination of both significantly lowered their free testosterone levels in comparison to the placebo group [37]. In this study, rosiglitazone, a PPAR $\gamma$ agonist improving lipotoxicity and insulin sensitivity, reduced androgen levels without any effect on insulin levels. This result suggests that PPAR $\gamma$ agonists may target the mechanisms by which insulin exaggeratedly stimulates androgen production in women with PCOS, thus restoring normal androgenic response to insulin.

It is important to mention that, in healthy women, inhibition of insulin secretion with diazoxide does not have any effect on their testosterone levels [38] and hyperinsulinemia during a euglycemic-hyperinsulinemic clamp does not increase their androgen production [39]. Accordingly, insulin does not seem to be related to androgen production in normal women, suggesting that androgenic hyperresponsiveness to insulin is specific to PCOS [9]. Taken together, these results suggest that insulin contributes to PCOS hyperandrogenemia even when insulin levels are normal and that women may develop PCOS because of androgenic hyperresponsiveness not only to ACTH and LH but also to insulin $[9,10]$. This is important because insulin levels can increase 
many folds with insulin resistance, while $\mathrm{LH}$ and ACTH levels are more stable.

Insulin also contributes to hyperandrogenemia in PCOS women by lowering the liver production of sex hormonebinding globulin (SHBG), which acts as a testosterone carrier in plasma and thus lowers free testosterone levels. Circulating SHBG levels are indeed lower in obese, hyperinsulinemic women with PCOS [40]. These low levels of SHBG were improved in obese women with PCOS by treatment with diazoxide for 10 days or acarbose for 6 months [35, 41]. Low SHBG levels are also found in insulin-resistant patients with prediabetes or type 2 diabetes [40].

2.4. Insulin Signaling Pathways in Women with PCOS (Figure 1). Most studies in women with PCOS were performed on insulin-sensitive tissues, such as muscle and adipose tissues, and also on fibroblasts that are easily accessible. In fibroblast [42] and muscle cells [43], it was found that serine phosphorylation of the insulin receptor or insulin receptor substrate- (IRS-) 1 is constitutively increased in PCOS women (see Figure 1, in red), which was associated with a reduction in tyrosine phosphorylation of the insulin receptor and IRS [42] and reduced PI3K activity. It was indeed clearly demonstrated in type 2 diabetes that signal transduction of the metabolic pathway of insulin is reduced when insulin receptors and IRS-1 or IRS-2 are serinephosphorylated instead of tyrosine-phosphorylated $[16,44]$. Accordingly, a study performed in muscular biopsies obtained during in vivo insulin infusion in obese PCOS women found that the association between IRS-1 and PI3K was altered, which was correlated with reduced in vivo glucose uptake [19]. Defective metabolic actions of insulin in PCOS women seem to involve initial insulin signaling steps and most likely result from abnormal serine phosphorylation rather than from defective protein expression.

Insulin mitogenic actions seem to be affected differently than metabolic actions in women with PCOS. In fibroblasts cultured from PCOS women, as compared to healthy controls, glucose uptake and glycogen synthesis were reduced, but no difference was seen in cell proliferation under insulin or IGF-1 stimulation [18]. Another study in skeletal muscle from PCOS women found that insulin-mediated activation of ERK1/2, an important mediator of the mitogenic pathway, was severely attenuated during an insulin-glucose clamp, as compared to control women [45] (see Figure 1, in red).

\subsection{Implication of Insulin Signaling Pathways in Androgen} Biosynthesis (Figure 1). Ovarian androgens are produced by theca cells, which surround granulosa cells, and by interstitial cells, which are scattered between follicles. Theca-interstitial cells express the enzyme P450c17 and are stimulated by $\mathrm{LH}$ (or hCG). Granulosa cells however, which are juxtaposed to theca cells and surround the oocyte, do not express P450c17 and convert theca-interstitial cell-derived androgens to estrogens under FSH stimulation. In women with PCOS, hyperandrogenemia is driven by high P450c17 and $3 \beta \mathrm{HSD}$ activities [46], the key enzymes of androgen biosynthesis. As illustrated in the right part of Figure 1, P450c17 has both $17 \alpha$-hydroxylase and 17,20-lyase activities [47-49], the latter generating the main androgen precursors, dehydroepiandrosterone (DHEA) and androstenedione. This lyase activity is favored by different factors, including serine/threonine phosphorylation of P450c17 [50]. Since P450c17 has a significant role in androgen production, any change in its expression or activity will therefore have an important impact on androgen production.

The cellular mechanisms by which insulin regulates androgen production are not well understood, but potential pathways are illustrated in Figure 1 [10]. Studies have shown that insulin potentiates androgen production in normal ovarian cell models [10], and even more so in cultured ovarian cells from PCOS women, through direct binding to its own receptor $[51,52]$. Specific blockade of PI3K in normal human theca cells markedly inhibits the combined insulin and LH stimulation of P450c17 activity [53]. Insulin may also stimulate P450c17 activity through some members of the MAPK pathway, such as p38 and JNK (for review, see [54] and Figure 1). Importantly, these pathways appear to be enhanced in women with PCOS $[55,56]$, as opposed to the PI3K pathway that was shown to be insulin resistant $[18,19,55,57,58]$. Furthermore, several findings suggest that a reduction of ERK1/2 signaling, another component of the MAPK insulin pathway, may increase androgen biosynthesis $[53,59,60]$ and be intrinsic to PCOS women [59]. Thus, the positive balance between p38/JNK/p54 and ERK insulin pathways seems to be characteristic of PCOS and to upregulate P450c17 activity and could therefore explain PCOS androgenic hyperresponsiveness. Interestingly, cellular overexposure to nonesterified fatty acid (NEFA), which leads to lipotoxicity, has been shown to inhibit ERK activity in other cell models and could therefore mimic this defect.

2.6. Lipotoxicity, Metabolic Insulin Resistance, and PCOS. Lipotoxicity refers to the cellular adverse consequences of NEFA [44]. Cellular NEFAs originate either from circulating NEFA or from triglycerides carried in the circulation by triglyceride-rich lipoproteins (chylomicrons and VLDL), which release NEFA under the action of lipoprotein lipase. Normal intracellular NEFA metabolism could be exceeded or impaired, as previously described in association with a genetic defect in mitochondrial $\beta$-oxidation in offspring of subjects with type 2 diabetes [61]. Our group has demonstrated in vivo that prolonged elevation of circulating NEFA reduces muscle and hepatic insulin sensitivity, as well as $\beta$-cell function, in normal subjects [38, 62-64]. This is one likely mechanism by which lipotoxicity can lead to global metabolic insulin resistance and diabetes [65]. Recent studies found that increasing circulating NEFA levels, using an infusion of intralipid and heparin, stimulates androgen production in healthy men [66] and women [67], suggesting that systemic NEFA overflow can also trigger androgen production in vivo.

Regarding intracellular mechanisms of lipotoxicity, it was shown that mitochondrial NEFA $\beta$-oxidation overload may lead to the formation of reactive lipids, such as diacylglycerol (DAG) and ceramides (for review, see [68]). These mediators activate the serine/threonine kinase cascade leading to serine phosphorylation of the insulin receptor and 


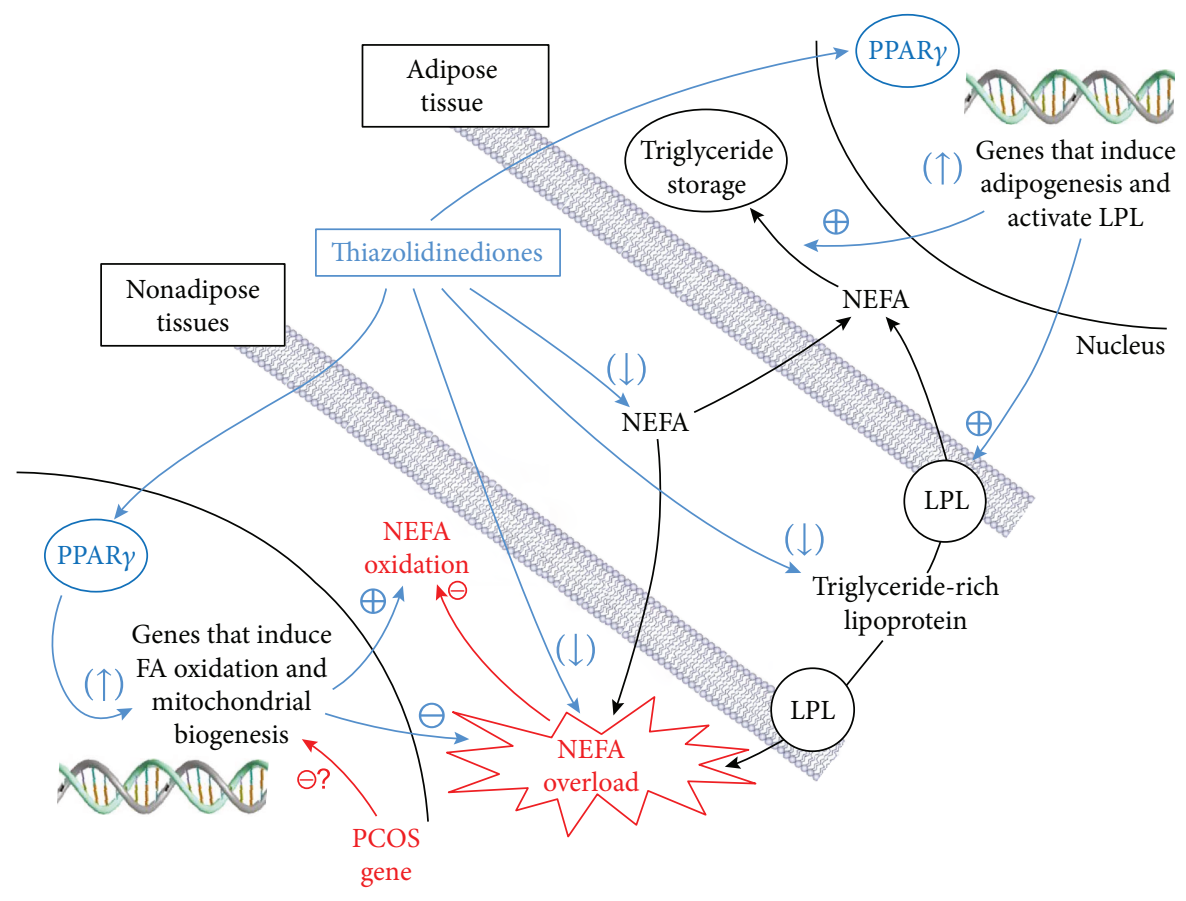

FIGURE 2: PPAR $\gamma$ and AT2R implications in PCOS-associated defects. PPAR $\gamma$ (and maybe AT2R) agonists increase tyrosine phosphorylation of IRS-1. Insulin-stimulated androgen production has been shown to be increased by specific inhibition of MEK. MEK/ERK activity was found to be constitutively reduced in PCOS women, inhibited by NEFAs, and activated by PPAR $\gamma$ agonists. AT2R activation counteracts lipotoxic effects of NEFA either directly or through activation of PPAR $\gamma$. Adapted from [10].

insulin receptor substrates (IRS-1/2), causing a decrease in PI3K activation [14, 69-73] (Figure 1). As mentioned above, constitutively increased serine phosphorylation levels of insulin receptors and IRS-1 have been found in PCOS skin fibroblasts [42, 74] and muscle cells [19, 43, 75]. Most importantly, it was shown that serine phosphorylation of P450c17 increases its 17,20-lyase activity [50] (Figure 1). Moreover, we demonstrated in bovine adrenal cells that, under LH pathway activation, the saturated fatty acid palmitate increases androgen production, concomitantly with a decrease in ERK1/2 phosphorylation [76], as previously observed in PCOS theca cells [59]. Thus, we demonstrated that lipotoxicity can directly trigger androgen overproduction in vitro, with inhibition of the MEK/ERK pathway as a potential mechanism. Furthermore, using follicular fluid as a surrogate of the intraovarian milieu, we showed that local gonadotropin-induced androgen production is associated with intraovarian exposure to lipids and that this association may be mediated by ineffective NEFA $\beta$-oxidation (Figure 1 , bottom left part) [77].

In this study, we also found that the inflammation was associated with androgen production as well, although to a lesser extent (reflected by IL-6) [77]. As for NEFA metabolites, the inflammation marker TNF- $\alpha$ is known to serinephosphorylate IRS-1 [78], thus contributing to insulin resistance. Indeed, systemic or low-grade tissue inflammation has been implicated in the development of metabolic disorders including type 2 diabetes [78]. On the other hand, inflammation may be triggered by lipotoxic effects $[14,79]$. Inflammation is therefore a potential mechanism for PCOS development, directly or as a mediator of lipotoxicity. The discussion of the role of inflammation in PCOS is beyond the scope of this review, and the reader is referred to a recent review from González [80].

While inducing lipotoxicity was shown to trigger androgen production in vivo and in vitro, improving lipotoxicity through PPAR $\gamma$ activation was also found to reduce androgen levels in women with PCOS [81]. In vivo studies showed that PPAR $\gamma$ agonists reduce PCOS androgenic hyperresponsiveness to $\mathrm{LH}[25,26]$ and ACTH $[28,32,33,82-85]$ and probably also to insulin [37]. As illustrated in Figure 2, activation of PPAR $\gamma$ improves lipotoxicity by two main mechanisms: (1) upregulation of key genes involved in NEFA and triglyceride storage in adipose tissue $[86,87]$. By promoting triglyceride storage in adipose tissues, PPAR $\gamma$ agonists reduce circulating NEFA [88] and thus prevent NEFA overexposure of nonadipose tissues [89]. (2) Upregulation of genes that are important for mitochondrial biogenesis and NEFA $\beta$-oxidation in nonadipose tissues [90]. In PCOS women, expression of these genes was reduced in skeletal muscle as compared to healthy women, which was associated with insulin resistance, and their expression was upregulated after treatment with a PPAR $\gamma$ agonist [91]. Furthermore, it was found that PPAR $\gamma$ is present in ovarian theca cells and that its activation impedes both $\mathrm{P} 450 \mathrm{c} 17$ activities and $\mathrm{LH}$ and/or insulin-stimulated testosterone production [92-94]. PPAR $\gamma$ agonists have also been shown to reverse the enhanced expression of $\mathrm{P} 450 \mathrm{c} 17$ induced by specific inhibition of MEK/ERK [60] (Figure 1). Thus, PPAR $\gamma$ seems implicated in androgen biosynthesis, and its activation may improve the balance between $\mathrm{p} 38 / \mathrm{JNK}$ and ERK pathways associated with PCOS androgenic hyperresponsiveness. 


\section{The Angiotensin II Type 2 Receptor: A New Target for the Management of Polycystic Ovary Syndrome}

3.1. The Renin-Angiotensin System and Angiotensin II Receptors. Several recent reviews, including ours, clearly implicate the renin-angiotensin system (RAS) in the development of insulin resistance, type 2 diabetes, and cardiovascular complications [95]. The RAS is mainly known for its role in regulating blood pressure. Indeed, when the juxtaglomerular cells in the kidney detect a drop in the circulating volume of plasmatic sodium levels, they secrete renin. This enzyme then cleaves the dodecapeptide angiotensinogen (produced by the liver) into decapeptide angiotensin I. Angiotensin I is then cleaved by the angiotensinconverting enzyme (ACE1), a carboxypeptidase which is located on the endothelial cells of capillaries, to form octapeptide angiotensin II [96]. Classically, angiotensin II (Ang II) mediates its action via the Ang II type 1 (AT1R) and type 2 (AT2R) receptors.

AT1R is expressed almost ubiquitously in the adult and is well known for being important in maintaining blood pressure and hydromineral balance [97]. Several studies have shown that chronic activation of the AT1R may contribute to insulin resistance and metabolic disorders in positive energy balance conditions [98-100]. Part of this action is mediated by AT1R-induced serine phosphorylation of the insulin receptor and IRS-1, thus inhibiting the downstream cascade of insulin signaling. Many reports have shown that AT2R activation reverses the negative action of AT1R on insulin receptor signaling (reviews: $[101,102]$ ) and this is one of the mechanisms by which AT2R might exert its beneficial effects on insulin resistance.

In contrast to AT1R, AT2R expression is low in most tissues [103], except for steroidogenic tissues such as adrenal glands and ovaries [104, 105]. However, it may be reexpressed in various disease states, including type 2 diabetes $[98,106,107]$. In the ovaries, AT1R and AT2R are localized in both theca and granulosa cells, in varying ratios according to the species [108]. In the ovary, it has been shown that AT2R activation (but not AT1R) stimulates conversion of androgen to estrogen $[109,110]$. Importantly, AT2R is known for inhibiting the excessive effects of AT1R in various experimental models [101, 102].

3.2. Benefits of Angiotensin II Type 2 Receptor Activation on Lipotoxicity and Androgen Production. Large clinical trials have provided evidence that AT1R blockers improve insulin sensitivity and help prevent type 2 diabetes [111, 112]. With regard to women with PCOS, a case series has shown that treatment of four obese and hypertensive PCOS women with the AT1R antagonist telmisartan caused a marked reduction in the androgen levels of all four women and improved menstrual cyclicity in three of the women [113]. These benefits were achieved despite a nonsignificant change of fasting insulin levels in these women who were not severely insulin resistant at the baseline. Moreover, a prospective observational study found that treatment of ten overweight/obese and hypertensive PCOS women with the angiotensin- converting enzyme inhibitor lisinopril for 4 weeks caused a significant decrease in their free testosterone levels with no change in SHBG levels [114]. A meta-analysis has also suggested that polymorphisms of the angiotensin-converting enzyme gene were associated with increased risk of PCOS in Caucasian women [115]. These findings suggest that the renin-angiotensin system may play a role not only in insulin resistance and type 2 diabetes but also in the development or management of PCOS.

Of note, the effects of blocking AT1R may result not only from the inhibition of AT1R but also from unopposed activation of AT2R [98, 116]. However, prior to 2004, the role and impact of AT2R stimulation had been difficult to establish due to the absence of a selective and potent AT2R agonist. Fortunately, we and others have now extensively characterized the properties of a nonpeptide drug-like compound, C21/M24, which is a highly selective AT2R agonist [117].

Several animal in vivo studies showed that AT2R activation with C21/M24 counteracts many deleterious effects of AT1R activation [118, 119]. More importantly, using C21/ M24 and an AT2R-knockout (AT2R-KO) mouse model, our group put forward several lines of evidence supporting that the stimulation of AT2R could prevent lipotoxicity and its consequences. In primary cultures of rat preadipocytes, C21/M24 increased PPAR $\gamma$ expression and favored cell differentiation [120], which are important for the storage of NEFA in adipose tissue and the prevention of NEFA spillover to nonadipose tissues. Accordingly, C21/M24 treatment improved insulin resistance induced by 6 weeks of high-fat-high-fructose (HFHF) diet in Wistar rats [120]. These important results were recently confirmed by another group using a mouse model of type 2 diabetes [100]. Furthermore, it was found that tissue NEFA uptake, measured with the ${ }^{18}$ F-FTHA tracer, was greater in AT2R-KO mice as compared to wild-type mice [121], including in adrenal glands (unpublished, mouse ovaries were too small to assess). AT2R-KO mice were also unable to increase the size of their adipocytes during HF-HF feeding, as compared to WT mice [121]. This finding reflects the inability of AT2R-KO mice to store lipids and may explain the increase of NEFA uptake by their nonadipose tissues. Moreover, our study [120] and others [122] suggest that AT2R stimulation increases PPAR $\gamma$ expression and activation. This might be a mechanism by which AT2R improves adipose tissue function. Altogether, these results suggest a beneficial role for AT2R in preventing tissue NEFA overload and insulin resistance.

Since AT2R stimulation with C21/M24 was found to improve lipotoxicity, our group proposed that this compound could potentially treat the underlying cause of PCOS. Accordingly, female JCR:LA-cp/cp rats, an obese model of PCOS displaying hyperandrogenism, insulin resistance, and polycystic ovaries, were treated with C21/M24 or intraperitoneal saline implants [123]. After only 7 days, C21/M24 treatment improved slightly and nonsignificantly insulin and NEFA levels in PCOS/ $c p$ rats as compared to saline but was able to normalize testosterone levels and ovarian NEFA uptake (measured using the ${ }^{18}$ F-FTHA tracer). When combining both PCOS/ $c p$ rat groups, testosterone levels were positively correlated with NEFA levels and even more 


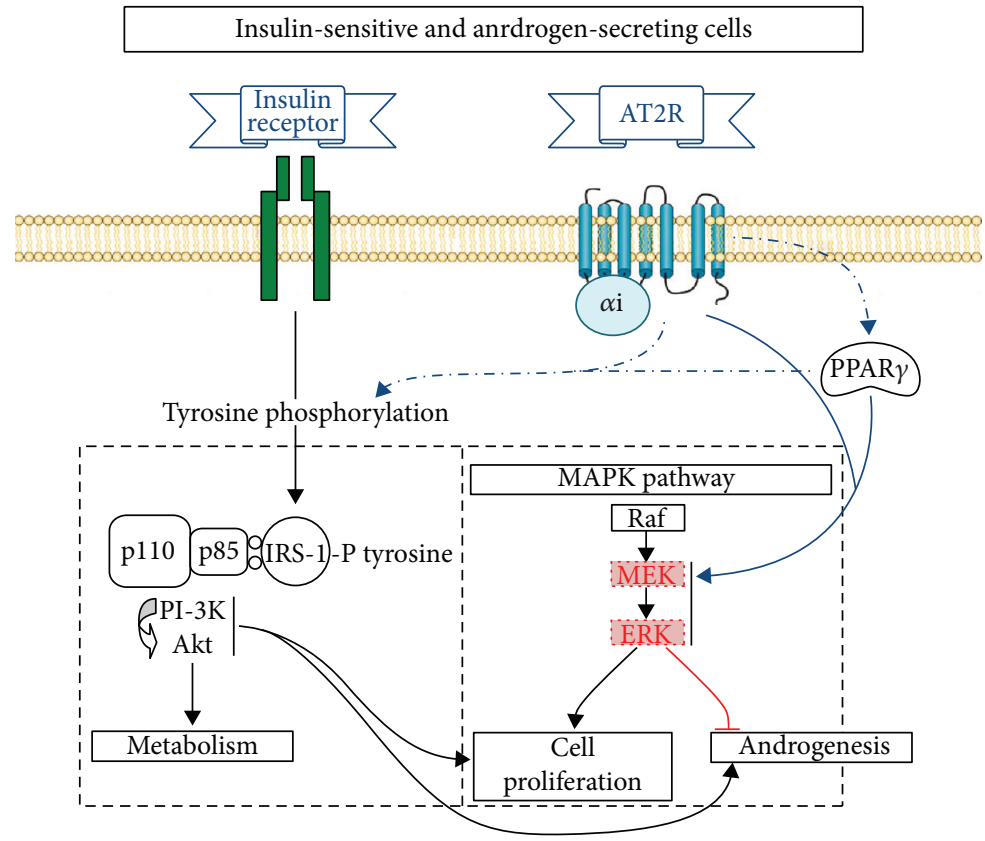

FIGURE 3: Whole-body and cellular mechanisms of PPAR effects. At the adipocyte level, activation of peroxisome proliferator-activated receptors $(\mathrm{PPAR} \gamma)$ increases the transcription of genes that induce adipogenesis as well as lipoprotein lipase (LPL) activation, which promotes the uptake of triglycerides by adipocytes. At the level of nonadipose tissues, activation of PPAR $\gamma$ increases the transcription of genes that induce fatty acid (FA) oxidation and mitochondrial biogenesis, which decrease intracellular overload of FA and FA metabolites. A PPAR $\gamma$-induced reduction of circulating levels of nonesterified FA (NEFA) and triglyceride-rich lipoprotein contributes to the decrease in NEFA uptake by nonadipose tissues and the overload of NEFAs in these tissues.

strongly with ovarian NEFA uptake. These results suggest that direct stimulation of AT2R with C21/M24 improves rapidly and predominantly ovarian NEFA uptake and androgen production in obese, insulin-resistant PCOS rats.

\subsection{Angiotensin II Type 2 Receptor Signal Transduction} Mechanisms (Figure 3). Despite the great deal of interest recently generated by the AT2R and its nonpeptide agonist C12/M24, the precise mechanisms by which the AT2R conveys its signals are not yet completely understood. While the AT2R is a G protein-coupled receptor, it is considered having atypical transduction mechanisms. Indeed, the stimulation of AT2R does not affect classical second messengers, such as the modulation of cAMP or production of $\mathrm{InsP}_{3}$ or DAG $[124,125]$. In vitro studies reported that the $\mathrm{G} \alpha \mathrm{i}$ protein could bind to and be activated by the AT2R, suggesting that it may be a signaling pathway for AT2R [126, 127]. Indeed, AT2R stimulation was shown to activate nitric oxide (NO) synthase, which is known to be induced by G $\alpha \mathrm{i}$, and to increase both NO and cGMP in a G $\alpha$ i protein-dependent manner. This pathway would be necessary for cell differentiation and migration mediated by the AT2R [128, 129].

Furthermore, depending on the model used, stimulation of the AT2R was shown to activate different tyrosine and serine/threonine phosphatases such as SHP-1, MKP-1, and PP2A, which can lead to transient inhibition of ERK1/2 and insulin signaling [130-136]. On the other hand, it was shown that AT2R can also induce sustained activation of ERK1/2 through the activation of Rap1/B-Raf $[137,138]$. It is therefore possible that this sustained activation of ERK1/
2 could counterbalance the inhibition of ERK1/2 that was observed in PCOS theca cells and that can be induced by NEFA (see Figures 1 and 3). Since constitutive inhibition of ERK1/2 was associated with higher androgen-secreting potential of theca cells (see previous sections and Figure 1), the ability of AT2R to activate ERK1/2 may play a role in correcting the NEFA-induced androgen hyperresponsiveness that characterizes women with PCOS (see Figure 3). Furthermore, it was shown in a cell line that AT2R stimulation is able to increase the expression of PPAR $\gamma$ and its activity [122].

Taken together, these potential mechanisms of AT2R action indicate that this receptor could be very useful in correcting PCOS hyperandrogenism. Indeed, as illustrated in Figure 3, most of the factors that were identified as playing a role in the hyperandrogenism of women with PCOS, such as lipotoxicity, reduced MEK/ERK activity, and insulin resistance, could potentially be corrected by AT2R-specific activation.

\section{Conclusion}

In summary, we put forward in this review the hypothesis that NEFA-induced lipotoxicity may explain both the hyperandrogenemia and insulin resistance that characterize PCOS women. Indeed, the literature including our own contributions suggests that PCOS hyperandrogenemia may be due to overexposure of androgen-secreting tissues to NEFA and/or defective intracellular NEFA metabolism, leading to lipotoxic effects. Lipotoxicity could therefore be the cause of androgenic hyperresponsiveness to insulin, $\mathrm{LH}$, and ACTH. 
Lipotoxicity is also well known to cause insulin resistance, which induces compensatory hyperinsulinemia and further increases hyperandrogenemia in many women with PCOS. On the other hand, treatments that reduce lipotoxicity, such as PPAR $\gamma$ agonists, improve systemic and cellular metabolism of NEFA and have been shown to treat PCOS hyperandrogenemia. Furthermore, our group and others recently found that AT2R activation is also able to improve lipotoxicity. We discussed evidence showing that AT2R signaling improves adipocyte size and nonadipose tissue NEFA uptake and might therefore prevent lipotoxicity and insulin resistance. Altogether, this review of the literature pleads in favor of the development of new approaches or pharmacologic treatments targeting lipotoxicity, such as the newly developed agonist C21/M24, for the management of both short-term symptoms and long-term cardiometabolic consequences of PCOS.

\section{Additional Points}

Copyright and Permission. To the best of our knowledge, the materials included in this chapter do not violate copyright laws. All original sources have been appropriately acknowledged and/or referenced. Where relevant, appropriate permissions have been obtained from the original copyright holders.

\section{Conflicts of Interest}

The authors declare no potential conflict of interest with respect to research, authorship, and/or publication of this article.

\section{References}

[1] R. Azziz, E. Carmina, D. Dewailly et al., "The Androgen Excess and PCOS Society criteria for the polycystic ovary syndrome: the complete task force report," Fertility and Sterility, vol. 91, no. 2, pp. 456-488, 2009.

[2] M. Brassard, Y. Ainmelk, and J. P. Baillargeon, "Basic infertility including polycystic ovary syndrome," Medical Clinics of North America, vol. 92, no. 5, pp. 1163-1192, 2008.

[3] R. Azziz, L. A. Sanchez, E. S. Knochenhauer et al., "Androgen excess in women: experience with over 1000 consecutive patients," The Journal of Clinical Endocrinology \& Metabolism, vol. 89, no. 2, pp. 453-462, 2004.

[4] C. J. Glueck, R. Papanna, P. Wang, N. Goldenberg, and L. Sieve-Smith, "Incidence and treatment of metabolic syndrome in newly referred women with confirmed polycystic ovarian syndrome," Metabolism, Clinical and Experimental, vol. 52, no. 7, pp. 908-915, 2003.

[5] R. S. Legro, A. R. Kunselman, and A. Dunaif, "Prevalence and predictors of dyslipidemia in women with polycystic ovary syndrome," The American Journal of Medicine, vol. 111, no. 8, pp. 607-613, 2001.

[6] D. A. Ehrmann, R. B. Barnes, R. L. Rosenfield, M. K. Cavaghan, and J. Imperial, "Prevalence of impaired glucose tolerance and diabetes in women with polycystic ovary syndrome," Diabetes Care, vol. 22, no. 1, pp. 141-146, 1999.
[7] M. R. Palmert, C. M. Gordon, A. I. Kartashov, R. S. Legro, S. J. Emans, and A. Dunaif, "Screening for abnormal glucose tolerance in adolescents with polycystic ovary syndrome," The Journal of Clinical Endocrinology \& Metabolism, vol. 87, no. 3, pp. 1017-1023, 2002.

[8] A. Dunaif, "Insulin action in the polycystic ovary syndrome," Endocrinology and Metabolism Clinics of North America, vol. 28, no. 2, pp. 341-359, 1999.

[9] J.-P. Baillargeon and J. E. Nestler, "Polycystic ovary syndrome: a syndrome of ovarian hypersensitivity to insulin?," The Journal of Clinical Endocrinology \& Metabolism, vol. 91, no. 1, pp. 22-24, 2006.

[10] J.-P. Baillargeon and R. Azziz, "Insulin action in polycystic ovary syndrome: in vivo and in vitro," in The Polycystic Ovary Syndrome: Current Concepts on Pathogenesis and Clinical Care, pp. 43-68, Springer, New York, NY, USA, 2007.

[11] A. J. Morales, G. A. Laughlin, T. Butzow, H. Maheshwari, G. Baumann, and S. S. Yen, "Insulin, somatotropic, and luteinizing hormone axes in lean and obese women with polycystic ovary syndrome: common and distinct features," The Journal of Clinical Endocrinology \& Metabolism, vol. 81, no. 8, pp. 2854-2864, 1996.

[12] K. H. Park, J. Y. Kim, C. W. Ahn, Y. D. Song, S. K. Lim, and H. C. Lee, "Polycystic ovarian syndrome (PCOS) and insulin resistance," International Journal of Gynaecology \& Obstetrics, vol. 74, no. 3, pp. 261-267, 2001.

[13] V. T. Samuel and G. I. Shulman, "The pathogenesis of insulin resistance: integrating signaling pathways and substrate flux," The Journal of Clinical Investigation, vol. 126, no. 1, pp. 12-22, 2016.

[14] A. C. Carpentier, "Postprandial fatty acid metabolism in the development of lipotoxicity and type 2 diabetes," Diabetes \& Metabolism, vol. 34, no. 2, pp. 97-107, 2008.

[15] H. J. Teede, M. L. Misso, A. A. Deeks et al., "Assessment and management of polycystic ovary syndrome: summary of an evidence-based guideline," The Medical Journal of Australia, vol. 195, Supplement 6, pp. S65-112, 2011.

[16] A. R. Saltiel and C. R. Kahn, "Insulin signalling and the regulation of glucose and lipid metabolism," Nature, vol. 414, no. 6865, pp. 799-806, 2001.

[17] T. P. Ciaraldi, A. el-Roeiy, Z. Madar, D. Reichart, J. M. Olefsky, and S. S. Yen, "Cellular mechanisms of insulin resistance in polycystic ovarian syndrome," The Journal of Clinical Endocrinology \& Metabolism, vol. 75, no. 2, pp. 577-583, 1992.

[18] C. B. Book and A. Dunaif, "Selective insulin resistance in the polycystic ovary syndrome," The Journal of Clinical Endocrinology \& Metabolism, vol. 84, no. 9, pp. 3110-3116, 1999.

[19] A. Dunaif, X. Wu, A. Lee, and E. Diamanti-Kandarakis, "Defects in insulin receptor signaling in vivo in the polycystic ovary syndrome (PCOS)," American Journal of Physiology-Endocrinology and Metabolism, vol. 281, no. 2, pp. E392-E399, 2001.

[20] A. Dunaif, K. R. Segal, D. R. Shelley, G. Green, A. Dobrjansky, and T. Licholai, "Evidence for distinctive and intrinsic defects in insulin action in polycystic ovary syndrome," Diabetes, vol. 41, no. 10, pp. 1257-1266, 1992.

[21] J. Holte, T. Bergh, C. Berne, L. Berglund, and H. Lithell, "Enhanced early insulin response to glucose in relation to insulin resistance in women with polycystic ovary syndrome 
and normal glucose tolerance," The Journal of Clinical Endocrinology \& Metabolism, vol. 78, no. 5, pp. 1052-1058, 1994.

[22] L. C. Morin-Papunen, I. Vauhkonen, R. M. Koivunen, A. Ruokonen, and J. S. Tapanainen, "Insulin sensitivity, insulin secretion, and metabolic and hormonal parameters in healthy women and women with polycystic ovarian syndrome," Human Reproduction, vol. 15, no. 6, pp. 1266$1274,2000$.

[23] P. Björntorp, "Body fat distribution, insulin resistance, and metabolic diseases," Nutrition, vol. 13, no. 9, pp. 795-803, 1997.

[24] M. Ciampelli, A. M. Fulghesu, F. Cucinelli et al., "Heterogeneity in beta cell activity, hepatic insulin clearance and peripheral insulin sensitivity in women with polycystic ovary syndrome," Human Reproduction, vol. 12, no. 9, pp. 1897-1901, 1997.

[25] C. Gilling-Smith, H. Story, V. Rogers, and S. Franks, "Evidence for a primary abnormality of thecal cell steroidogenesis in the polycystic ovary syndrome," Clinical Endocrinology, vol. 47, no. 1, pp. 93-99, 1997.

[26] L. Ibanez, J. E. Hall, N. Potau, A. Carrascosa, N. Prat, and A. E. Taylor, "Ovarian 17-hydroxyprogesterone hyperresponsiveness to gonadotropin-releasing hormone $(\mathrm{GnRH})$ agonist challenge in women with polycystic ovary syndrome is not mediated by luteinizing hormone hypersecretion: evidence from GnRH agonist and human chorionic gonadotropin stimulation testing," The Journal of Clinical Endocrinology \& Metabolism, vol. 81, no. 11, pp. 4103-4107, 1996.

[27] R. Azziz, V. Black, G. A. Hines, L. M. Fox, and L. R. Boots, "Adrenal androgen excess in the polycystic ovary syndrome: sensitivity and responsivity of the hypothalamic-pituitaryadrenal axis," The Journal of Clinical Endocrinology \& Metabolism, vol. 83, no. 7, pp. 2317-2323, 1998.

[28] S. A. Arslanian, V. Lewy, K. Danadian, and R. Saad, "Metformin therapy in obese adolescents with polycystic ovary syndrome and impaired glucose tolerance: amelioration of exaggerated adrenal response to adrenocorticotropin with reduction of insulinemia/insulin resistance," The Journal of Clinical Endocrinology \& Metabolism, vol. 87, no. 4, pp. 1555-1559, 2002.

[29] M. Guido, D. Romualdi, R. Suriano et al., "Effect of pioglitazone treatment on the adrenal androgen response to corticotrophin in obese patients with polycystic ovary syndrome," Human Reproduction, vol. 19, no. 3, pp. 534-539, 2004.

[30] A. la Marca, T. O. Egbe, G. Morgante, T. Paglia, A. Ciani, and V. de Leo, "Metformin treatment reduces ovarian cytochrome P-450c17 $\alpha$ response to human chorionic gonadotrophin in women with insulin resistance-related polycystic ovary syndrome," Human Reproduction, vol. 15, no. 1, pp. 21-23, 2000.

[31] J. E. Nestler and D. J. Jakubowicz, "Decreases in ovarian cytochrome P450c17 $\alpha$ activity and serum free testosterone after reduction of insulin secretion in polycystic ovary syndrome," The New England Journal of Medicine, vol. 335, no. 9, pp. 617-623, 1996.

[32] J. Devesa, R. Perez-Fernandez, L. Lima, and J. CabezasCerrato, "Adrenal cortex and type II polycystic ovary syndrome," Gynecological Endocrinology, vol. 1, no. 3, pp. 269-277, 1987.

[33] R. J. Chang, L. R. Laufer, D. R. Meldrum et al., "Steroid secretion in polycystic ovarian disease after ovarian suppression by a long-acting gonadotropin-releasing hormone agonist," The
Journal of Clinical Endocrinology \& Metabolism, vol. 56, no. 5, pp. 897-903, 1983.

[34] J. O. H. N. E. Nestler, C. O. Barlascini, D. W. Matt et al., "Suppression of serum insulin by diazoxide reduces serum testosterone levels in obese women with polycystic ovary syndrome," The Journal of Clinical Endocrinology \& Metabolism, vol. 68, no. 6, pp. 1027-1032, 1989.

[35] I. A. A. Penna, P. R. B. Canella, R. M. Reis, M. F. Silva de Sa, and R. A. Ferriani, "Acarbose in obese patients with polycystic ovarian syndrome: a double-blind, randomized, placebocontrolled study," Human Reproduction, vol. 20, no. 9, pp. 2396-2401, 2005.

[36] J.-P. Baillargeon and A. Carpentier, "Role of insulin in the hyperandrogenemia of lean women with polycystic ovary syndrome and normal insulin sensitivity," Fertility and Sterility, vol. 88, no. 4, pp. 886-893, 2007.

[37] J. Baillargeon, D. Jakubowicz, M. Iuorno, S. Jakubowicz, and J. Nestler, "Effects of metformin and rosiglitazone, alone and in combination, in nonobese women with polycystic ovary syndrome and normal indices of insulin sensitivity," Fertility and Sterility, vol. 82, no. 4, pp. 893-902, 2004.

[38] A. C. Carpentier, F. Frisch, D. Cyr et al., "On the suppression of plasma nonesterified fatty acids by insulin during enhanced intravascular lipolysis in humans," American Journal of Physiology-Endocrinology and Metabolism, vol. 289, no. 5, pp. E849-E856, 2005.

[39] J. E. Nestler, J. N. Clore, J. F. Strauss III, and W. G. Blackard, "The effects of hyperinsulinemia on serum testosterone, progesterone, dehydroepiandrosterone sulfate, and cortisol levels in normal women and in a woman with hyperandrogenism, insulin resistance, and acanthosis nigricans," The Journal of Clinical Endocrinology \& Metabolism, vol. 64, no. 1, pp. 180-184, 1987.

[40] E. L. Ding, Y. Song, J. A. E. Manson et al., "Sex hormonebinding globulin and risk of type 2 diabetes in women and men," The New England Journal of Medicine, vol. 361, no. 12, pp. 1152-1163, 2009.

[41] J. E. Nestler, L. P. Powers, D. W. Matt et al., “A direct effect of hyperinsulinemia on serum sex hormone-binding globulin levels in obese women with the polycystic ovary syndrome," The Journal of Clinical Endocrinology \& Metabolism, vol. 72, no. 1, pp. 83-89, 1991.

[42] A. Dunaif, J. Xia, C. B. Book, E. Schenker, and Z. Tang, "Excessive insulin receptor serine phosphorylation in cultured fibroblasts and in skeletal muscle. A potential mechanism for insulin resistance in the polycystic ovary syndrome," The Journal of Clinical Investigation, vol. 96, no. 2, pp. 801-810, 1995.

[43] A. Corbould, Y.-B. Kim, J. F. Youngren et al., "Insulin resistance in the skeletal muscle of women with PCOS involves intrinsic and acquired defects in insulin signaling," American Journal of Physiology-Endocrinology and Metabolism, vol. 288, no. 5, pp. E1047-E1054, 2005.

[44] R. A. Defronzo, "Dysfunctional fat cells, lipotoxicity and type 2 diabetes," International Journal of Clinical Practice, vol. 58, pp. 9-21, 2004.

[45] M. Rajkhowa, S. Brett, D. J. Cuthbertson et al., "Insulin resistance in polycystic ovary syndrome is associated with defective regulation of ERK1/2 by insulin in skeletal muscle in vivo," Biochemical Journal, vol. 418, no. 3, pp. 665-671, 2009. 
[46] V. L. Nelson, R. S. Legro, J. F. Strauss III, and J. M. McAllister, "Augmented androgen production is a stable steroidogenic phenotype of propagated theca cells from polycystic ovaries," Molecular Endocrinology, vol. 13, no. 6, pp. 946-957, 1999.

[47] B. J. Brock and M. R. Waterman, "Biochemical differences between rat and human cytochrome P450c17 support the different steroidogenic needs of these two species," Biochemistry, vol. 38, no. 5, pp. 1598-1606, 1999.

[48] A. Endoh, S. B. Kristiansen, P. R. Casson, J. E. Buster, and P. J. Hornsby, "The zona reticularis is the site of biosynthesis of dehydroepiandrosterone and dehydroepiandrosterone sulfate in the adult human adrenal cortex resulting from its low expression of 3 beta-hydroxysteroid dehydrogenase," The Journal of Clinical Endocrinology \& Metabolism, vol. 81, no. 10, pp. 3558-3565, 1996.

[49] P. J. Hyatt, K. Bhatt, and J. F. Tait, "Steroid biosynthesis by zona fasciculata and zona reticularis cells purified from the mammalian adrenal cortex," Journal of Steroid Biochemistry, vol. 19, no. 1, pp. 953-959, 1983.

[50] L. H. Zhang, H. Rodriguez, S. Ohno, and W. L. Miller, "Serine phosphorylation of human P450c17 increases 17,20-lyase activity: implications for adrenarche and the polycystic ovary syndrome," Proceedings of the National Academy of Sciences of the United States of America, vol. 92, no. 23, pp. 10619-10623, 1995.

[51] J. E. Nestler, D. J. Jakubowicz, A. Falcon de Vargas, C. Brik, N. Quintero, and F. Medina, "Insulin stimulates testosterone biosynthesis by human thecal cells from women with polycystic ovary syndrome by activating its own receptor and using inositolglycan mediators as the signal transduction system," The Journal of Clinical Endocrinology and Metabolism, vol. 83, no. 6, pp. 2001-2005, 1998.

[52] E. R. Hernandez, C. E. Resnick, W. D. Holtzclaw, D. W. Payne, and E. Y. Adashi, "Insulin as a regulator of androgen biosynthesis by cultured rat ovarian cells: cellular mechanism(s) underlying physiological and pharmacological hormonal actions," Endocrinology, vol. 122, no. 5, pp. 20342043, 1988.

[53] I. Munir, H.-W. W. Yen, D. H. Geller et al., "Insulin augmentation of $17 \alpha$-hydroxylase activity is mediated by phosphatidyl inositol 3-kinase but not extracellular signal-regulated kinase-1/2 in human ovarian theca cells," Endocrinology, vol. 145, no. 1, pp. 175-183, 2004.

[54] J. K. Wickenheisser, J. M. Biegler, V. L. Nelson-DeGrave, R. S. Legro, J. F. Strauss, and J. M. McAllister, "Cholesterol sidechain cleavage gene expression in theca cells: augmented transcriptional regulation and mRNA stability in polycystic ovary syndrome," PLoS One, vol. 7, no. 11, article e48963, 2012.

[55] X. K. Wu, S. Y. Zhou, J. X. Liu et al., "Selective ovary resistance to insulin signaling in women with polycystic ovary syndrome," Fertility and Sterility, vol. 80, no. 4, pp. 954-965, 2003.

[56] A. Corbould, H. Zhao, S. Mirzoeva, F. Aird, and A. Dunaif, "Enhanced mitogenic signaling in skeletal muscle of women with polycystic ovary syndrome," Diabetes, vol. 55, no. 3, pp. 751-759, 2006.

[57] S. Rice, N. Christoforidis, C. Gadd et al., "Impaired insulin-dependent glucose metabolism in granulosa-lutein cells from anovulatory women with polycystic ovaries," Human Reproduction, vol. 20, no. 2, pp. 373-381, 2005.
[58] E. Diamanti-Kandarakis and A. Dunaif, "Insulin resistance and the polycystic ovary syndrome revisited: an update on mechanisms and implications," Endocrine Reviews, vol. 33, no. 6, pp. 981-1030, 2012.

[59] V. L. Nelson-Degrave, J. K. Wickenheisser, K. L. Hendricks et al., "Alterations in mitogen-activated protein kinase kinase and extracellular regulated kinase signaling in theca cells contribute to excessive androgen production in polycystic ovary syndrome," Molecular Endocrinology, vol. 19, no. 2, pp. 379-390, 2005.

[60] P. Kempna, G. Hofer, P. E. Mullis, and C. E. Fluck, "Pioglitazone inhibits androgen production in NCI-H295R cells by regulating gene expression of CYP17 and HSD3B2," Molecular Pharmacology, vol. 71, no. 3, pp. 787-798, 2007.

[61] K. F. Petersen, S. Dufour, D. Befroy, R. Garcia, and G. I. Shulman, "Impaired mitochondrial activity in the insulinresistant offspring of patients with type 2 diabetes," The New England Journal of Medicine, vol. 350, no. 7, pp. 664671, 2004.

[62] A. Carpentier, S. D. Mittelman, B. Lamarche, R. N. Bergman, A. Giacca, and G. F. Lewis, "Acute enhancement of insulin secretion by FFA in humans is lost with prolonged FFA elevation," The American Journal of Physiology, vol. 276, no. 6, pp. E1055-E1066, 1999.

[63] A. Carpentier, S. D. Mittelman, R. N. Bergman, A. Giacca, and G. F. Lewis, "Prolonged elevation of plasma free fatty acids impairs pancreatic beta-cell function in obese nondiabetic humans but not in individuals with type 2 diabetes," Diabetes, vol. 49, no. 3, pp. 399-408, 2000.

[64] A. Carpentier, B. Zinman, N. Leung et al., "Free fatty acidmediated impairment of glucose-stimulated insulin secretion in nondiabetic Oji-Cree individuals from the Sandy Lake community of Ontario, Canada: a population at very high risk for developing type 2 diabetes," Diabetes, vol. 52, no. 6, pp. 1485-1495, 2003.

[65] G. Boden, "Role of fatty acids in the pathogenesis of insulin resistance and NIDDM," Diabetes, vol. 46, no. 1, pp. 3-10, 1997.

[66] K. Mai, T. Bobbert, V. Kullmann et al., "Free fatty acids increase androgen precursors in vivo," The Journal of Clinical Endocrinology \& Metabolism, vol. 91, no. 4, pp. 1501-1507, 2006.

[67] K. Mai, T. Bobbert, F. Reinecke et al., "Intravenous lipid and heparin infusion-induced elevation in free fatty acids and triglycerides modifies circulating androgen levels in women: a randomized, controlled trial," The Journal of Clinical Endocrinology and Metabolism, vol. 93, no. 10, pp. 3900-3906, 2008.

[68] V. Poitout, J. Amyot, M. Semache, B. Zarrouki, D. Hagman, and G. Fontes, "Glucolipotoxicity of the pancreatic beta cell," Biochimica et Biophysica Acta (BBA) - Molecular and Cell Biology of Lipids, vol. 1801, no. 3, pp. 289-298, 2010.

[69] G. I. Shulman, "Cellular mechanisms of insulin resistance," Journal of Clinical Investigation, vol. 106, no. 2, pp. 171176, 2000.

[70] M. E. Griffin, M. J. Marcucci, G. W. Cline et al., "Free fatty acid-induced insulin resistance is associated with activation of protein kinase $\mathrm{C}$ theta and alterations in the insulin signaling cascade," Diabetes, vol. 48, no. 6, pp. 1270-1274, 1999.

[71] C. Yu, Y. Chen, G. W. Cline et al., "Mechanism by which fatty acids inhibit insulin activation of insulin receptor substrate-1 (IRS-1)-associated phosphatidylinositol 3-kinase activity in 
muscle," The Journal of Biological Chemistry, vol. 277, no. 52, pp. 50230-50236, 2002.

[72] S. I. Itani, N. B. Ruderman, F. Schmieder, and G. Boden, "Lipid-induced insulin resistance in human muscle is associated with changes in diacylglycerol, protein kinase $\mathrm{C}$, and IkappaB-alpha," Diabetes, vol. 51, no. 7, pp. 2005-2011, 2002.

[73] A. Dresner, D. Laurent, M. Marcucci et al., "Effects of free fatty acids on glucose transport and IRS-1-associated phosphatidylinositol 3-kinase activity," The Journal of Clinical Investigation, vol. 103, no. 2, pp. 253-259, 1999.

[74] M. Li, J. F. Youngren, A. Dunaif et al., "Decreased insulin receptor (IR) autophosphorylation in fibroblasts from patients with PCOS: effects of serine kinase inhibitors and IR activators," The Journal of Clinical Endocrinology \& Metabolism, vol. 87, no. 9, pp. 4088-4093, 2002.

[75] K. Højlund, D. Glintborg, N. R. Andersen et al., "Impaired insulin-stimulated phosphorylation of Akt and AS160 in skeletal muscle of women with polycystic ovary syndrome is reversed by pioglitazone treatment," Diabetes, vol. 57 , no. 2 , pp. 357-366, 2008.

[76] S. Bellanger, M. C. Battista, G. D. Fink, and J. P. Baillargeon, "Saturated fatty acid exposure induces androgen overproduction in bovine adrenal cells," Steroids, vol. 77, no. 4, pp. 347353, 2012.

[77] A. Gervais, M.-C. Battista, B. Carranza-Mamane, H. B. Lavoie, and J.-P. Baillargeon, "Follicular fluid concentrations of lipids and their metabolites are associated with intraovarian gonadotropin-stimulated androgen production in women undergoing in vitro fertilization," The Journal of Clinical Endocrinology \& Metabolism, vol. 100, no. 5, pp. 1845-1854, 2015.

[78] G. S. Hotamisligil, P. Peraldi, A. Budavari, R. Ellis, M. F. White, and B. M. Spiegelman, "IRS-1-mediated inhibition of insulin receptor tyrosine kinase activity in TNF- $\alpha$ - and obesity-induced insulin resistance," Science, vol. 271, no. 5249, pp. 665-670, 1996.

[79] F. Kim, M. Pham, I. Luttrell et al., "Toll-like receptor-4 mediates vascular inflammation and insulin resistance in diet-induced obesity," Circulation Research, vol. 100, no. 11, pp. 1589-1596, 2007.

[80] F. González, "Nutrient-induced inflammation in polycystic ovary syndrome: role in the development of metabolic aberration and ovarian dysfunction," Seminars in Reproductive Medicine, vol. 33, no. 4, pp. 276-286, 2015.

[81] D. A. Ehrmann, D. J. Schneider, B. E. Sobel et al., “Troglitazone improves defects in insulin action, insulin secretion, ovarian steroidogenesis, and fibrinolysis in women with polycystic ovary syndrome," The Journal of Clinical Endocrinology \& Metabolism, vol. 82, no. 7, pp. 2108-2116, 1997.

[82] S. F. Witchel and P. A. Lee, "Human chorionic gonadotropin stimulation to assess for ovarian hyperandrogenism," Journal of Pediatric and Adolescent Gynecology, vol. 11, no. 2, pp. 73-78, 1998.

[83] R. Colak, F. Kelestimur, K. Unluhizarci, F. Bayram, Y. Sahin, and A. Tutus, "A comparison between the effects of low dose $(1$ microg) and standard dose $(250$ microg $)$ ACTH stimulation tests on adrenal P450c17alpha enzyme activity in women with polycystic ovary syndrome," European Journal of Endocrinology, vol. 147, no. 4, pp. 473-477, 2002.

[84] R. S. Rittmaster, N. Deshwal, and L. Lehman, "The role of adrenal hyperandrogenism, insulin resistance, and obesity in the pathogenesis of polycystic ovarian syndrome," The
Journal of Clinical Endocrinology \& Metabolism, vol. 76, no. 5, pp. 1295-1300, 1993.

[85] A. Mongiò̀, M. Macchi, E. Vicari et al., "Pituitary and adrenal response to ovine corticotropin-releasing hormone in women with polycystic ovarian syndrome," Journal of Endocrinological Investigation, vol. 11, no. 9, pp. 637-640, 1988.

[86] S. A. Kliewer, H. E. Xu, M. H. Lambert, and T. M. Willson, "Peroxisome proliferator-activated receptors: from genes to physiology," Recent Progress in Hormone Research, vol. 56, no. 1, pp. 239-265, 2001.

[87] I. Bogacka, H. Xie, G. A. Bray, and S. R. Smith, "The effect of pioglitazone on peroxisome proliferator-activated receptor- $\gamma$ target genes related to lipid storage in vivo," Diabetes Care, vol. 27, no. 7, pp. 1660-1667, 2004.

[88] J. B. Buse, M. H. Tan, M. J. Prince, and P. P. Erickson, "The effects of oral anti-hyperglycaemic medications on serum lipid profiles in patients with type 2 diabetes," Diabetes, Obesity and Metabolism, vol. 6, no. 2, pp. 133-156, 2004.

[89] G. F. Lewis, A. Carpentier, K. Adeli, and A. Giacca, "Disordered fat storage and mobilization in the pathogenesis of insulin resistance and type 2 diabetes," Endocrine Reviews, vol. 23, no. 2, pp. 201-229, 2002.

[90] Z. Wu, P. Puigserver, U. Andersson et al., "Mechanisms controlling mitochondrial biogenesis and respiration through the thermogenic coactivator PGC-1," Cell, vol. 98, no. 1, pp. 115-124, 1999.

[91] V. Skov, D. Glintborg, S. Knudsen et al., "Pioglitazone enhances mitochondrial biogenesis and ribosomal protein biosynthesis in skeletal muscle in polycystic ovary syndrome," PLoS One, vol. 3, no. 6, article e2466, 2008.

[92] J. D. Veldhuis, G. Zhang, and J. C. Garmey, "Troglitazone, an insulin-sensitizing thiazolidinedione, represses combined stimulation by $\mathrm{LH}$ and insulin of de novo androgen biosynthesis by thecal cells in vitro," The Journal of Clinical Endocrinology \& Metabolism, vol. 87, no. 3, pp. 1129-1133, 2002.

[93] P. D. Schoppee, J. C. Garmey, and J. D. Veldhuis, "Putative activation of the peroxisome proliferator-activated receptor $\gamma$ impairs androgen and enhances progesterone biosynthesis in primary cultures of porcine theca cells," Biology of Reproduction, vol. 66, no. 1, pp. 190-198, 2002.

[94] D. Seto-Young, M. Paliou, J. Schlosser et al., "Direct thiazolidinedione action in the human ovary: insulin-independent and insulin-sensitizing effects on steroidogenesis and insulin-like growth factor binding protein-1 production," The Journal of Clinical Endocrinology \& Metabolism, vol. 90, no. 11, pp. 6099-6105, 2005.

[95] A. D. de Kloet, E. G. Krause, and S. C. Woods, "The renin angiotensin system and the metabolic syndrome," Physiology \& Behavior, vol. 100, no. 5, pp. 525-534, 2010.

[96] S. S. Karnik, H. Unal, J. R. Kemp et al., "International Union of Basic and Clinical Pharmacology. XCIX. Angiotensin receptors: interpreters of pathophysiological angiotensinergic stimuli," Pharmacological Reviews, vol. 67, no. 4, pp. 754819, 2015.

[97] M. de Gasparo, K. J. Catt, T. Inagami, J. W. Wright, and T. Unger, "International Union of Pharmacology. XXIII. The angiotensin II receptors," Pharmacological Reviews, vol. 52, no. 3, pp. 415-472, 2000.

[98] N. Gallo-Payet, M. Shum, J.-P. Baillargeon et al., “AT2 receptor agonists: exploiting the beneficial arm of Ang II 
signaling," Current Hypertension Reviews, vol. 8, no. 1, pp. 47-59, 2012.

[99] T. Ogihara, T. Asano, K. Ando et al., “Angiotensin II-induced insulin resistance is associated with enhanced insulin signaling," Hypertension, vol. 40, no. 6, pp. 872-879, 2002.

[100] K. Ohshima, M. Mogi, F. Jing et al., "Direct angiotensin II type 2 receptor stimulation ameliorates insulin resistance in type 2 diabetes mice with PPAR $\gamma$ activation," PLoS One, vol. 7, no. 11, article e48387, 2012.

[101] M. Horiuchi, M. Mogi, and M. Iwai, "Signaling crosstalk angiotensin II receptor subtypes and insulin," Endocrine Journal, vol. 53, no. 1, pp. 1-5, 2006.

[102] C. Morisco, G. Lembo, and B. Trimarco, "Insulin resistance and cardiovascular risk: new insights from molecular and cellular biology," Trends in Cardiovascular Medicine, vol. 16, no. 6, pp. 183-188, 2006.

[103] E. F. Grady, L. A. Sechi, C. A. Griffin, M. Schambelan, and J. E. Kalinyak, "Expression of AT2 receptors in the developing rat fetus," The Journal of Clinical Investigation, vol. 88, no. 3, pp. 921-933, 1991.

[104] L. Breault, J. G. Lehoux, and N. Gallo-Payet, “The angiotensin AT2 receptor is present in the human fetal adrenal gland throughout the second trimester of gestation," The Journal of Clinical Endocrinology \& Metabolism, vol. 81, no. 11, pp. 3914-3922, 1996.

[105] M. Tanaka, J. Ohnishi, Y. Ozawa et al., "Characterization of angiotensin II receptor type 2 during differentiation and apoptosis of rat ovarian cultured granulosa cells," Biochemical and Biophysical Research Communications, vol. 207, no. 2, pp. 593-598, 1995.

[106] C. Savoia, R. M. Touyz, M. Volpe, and E. L. Schiffrin, "Angiotensin type 2 receptor in resistance arteries of type 2 diabetic hypertensive patients," Hypertension, vol. 49, no. 2, pp. 341-346, 2007.

[107] C. A. Lemarie and E. L. Schiffrin, "The angiotensin II type 2 receptor in cardiovascular disease," Journal of the ReninAngiotensin-Aldosterone System, vol. 11, no. 1, pp. 19-31, 2009.

[108] P. B. Goncalves, R. Ferreira, B. Gasperin, and J. F. Oliveira, "Role of angiotensin in ovarian follicular development and ovulation in mammals: a review of recent advances," Reproduction, vol. 143, no. 1, pp. 11-20, 2012.

[109] A. G. Pucell, J. C. Hodges, I. Sen, F. M. Bumpus, and A. Husain, "Biochemical properties of the ovarian granulosa cell type 2-angiotensin II receptor," Endocrinology, vol. 128, no. 4, pp. 1947-1959, 1991.

[110] Y. Yoshimura, M. Karube, H. Aoki et al., “Angiotensin II induces ovulation and oocyte maturation in rabbit ovaries via the AT2 receptor subtype," Endocrinology, vol. 137, no. 4, pp. 1204-1211, 1996.

[111] A. J. Scheen, "Renin-angiotensin system inhibition prevents type 2 diabetes mellitus. Part 1 . A meta-analysis of randomised clinical trials," Diabetes \& Metabolism, vol. 30, no. 6, pp. 487-496, 2004.

[112] K. A. M. Jandeleit-Dahm, C. Tikellis, C. M. Reid, C. I. Johnston, and M. E. Cooper, "Why blockade of the reninangiotensin system reduces the incidence of new-onset diabetes," Journal of Hypertension, vol. 23, no. 3, pp. 463-473, 2005.

[113] M. Jensterle, A. Janez, B. Vrtovec et al., "Decreased androgen levels and improved menstrual pattern after angiotensin II receptor antagonist telmisartan treatment in four hypertensive patients with polycystic ovary syndrome: case series," Croatian Medical Journal, vol. 48, no. 6, pp. 864-870, 2007.

[114] B. Hacihanefioglu, A. Somunkiran, I. Mahmutoglu, A. Sercelik, S. Toptani, and E. Kervancioglu, "Effect of hypertension therapy with the angiotensin-converting enzyme inhibitor lisinopril on hyperandrogenism in women with polycystic ovary syndrome," Fertility and Sterility, vol. 77, no. 3, pp. 526-528, 2002.

[115] H. Jia, B. Wang, L. Yu, and Z. Jiang, "Association of angiotensin-converting enzyme gene insertion/deletion polymorphism with polycystic ovary syndrome: a meta-analysis," Journal of the Renin-Angiotensin-Aldosterone System, vol. 14, no. 3, pp. 255-262, 2013.

[116] L. Paulis and T. Unger, "Novel therapeutic targets for hypertension," Nature Reviews Cardiology, vol. 7, no. 8, pp. 431-441, 2010.

[117] Y. Wan, C. Wallinder, B. Plouffe et al., "Design, synthesis, and biological evaluation of the first selective nonpeptide $\mathrm{AT}_{2}$ receptor agonist," Journal of Medicinal Chemistry, vol. 47, no. 24, pp. 5995-6008, 2004.

[118] A. Rehman, A. Leibowitz, N. Yamamoto, Y. Rautureau, P. Paradis, and E. L. Schiffrin, "Angiotensin type 2 receptor agonist compound 21 reduces vascular injury and myocardial fibrosis in stroke-prone spontaneously hypertensive rats," Hypertension, vol. 59, no. 2, pp. 291-299, 2012.

[119] U. M. Steckelings, M. Larhed, A. Hallberg et al., "Non-peptide AT2-receptor agonists," Current Opinion in Pharmacology, vol. 11, no. 2, pp. 187-192, 2011.

[120] M. Shum, S. Pinard, M.-O. Guimond et al., "Angiotensin II type 2 receptor promotes adipocyte differentiation and restores adipocyte size in high-fat/high-fructose dietinduced insulin resistance in rats," American Journal of Physiology-Endocrinology and Metabolism, vol. 304, no. 2, pp. E197-E210, 2013.

[121] C. Noll, S. M. Labbé, S. Pinard et al., "Postprandial fatty acid uptake and adipocyte remodeling in angiotensin type 2 receptor-deficient mice fed a high-fat/high-fructose diet," Adipocytes, vol. 5, no. 1, pp. 43-52, 2016.

[122] Y. Zhao, A. Foryst-Ludwig, D. Bruemmer et al., "Angiotensin II induces peroxisome proliferator-activated receptor gamma in $\mathrm{PC12W}$ cells via angiotensin type 2 receptor activation," Journal of Neurochemistry, vol. 94, no. 5, pp. 1395-1401, 2005.

[123] S. Leblanc, M.-C. Battista, C. Noll et al., “Angiotensin II type 2 receptor stimulation improves fatty acid ovarian uptake and hyperandrogenemia in an obese rat model of polycystic ovary syndrome," Endocrinology, vol. 155, no. 9, pp. 3684-3693, 2014.

[124] D. T. Dudley, S. E. Hubbell, and R. M. Summerfelt, "Characterization of angiotensin II (AT2) binding sites in R3T3 cells," Molecular Pharmacology, vol. 40, no. 3, pp. 360-367, 1991.

[125] M. L. Webb, E. C.-K. Liu, R. B. Cohen et al., "Molecular characterization of angiotensin II type II receptors in rat pheochromocytoma cells," Peptides, vol. 13, no. 3, pp. 499508, 1992.

[126] J. Zhang and R. E. Pratt, "The $\mathrm{AT}_{2}$ receptor selectively associates with $\mathrm{G}_{\mathrm{i} \alpha 2}$ and $\mathrm{G}_{\mathrm{i} \alpha 3}$ in the rat fetus," The Journal of Biological Chemistry, vol. 271, no. 25, pp. 15026-15033, 1996.

[127] J. L. Hansen, G. Servant, T. J. Baranski, T. Fujita, T. Iiri, and S. P. Sheikh, "Functional reconstitution of the angiotensin II 
type 2 receptor and $\mathrm{G}_{\mathrm{i}}$ activation," Circulation Research, vol. 87, no. 9, pp. 753-759, 2000.

[128] L. Gendron, F. Côté, M. D. Payet, and N. Gallo-Payet, "Nitric oxide and cyclic GMP are involved in angiotensin II $\mathrm{AT}_{2}$ receptor effects on neurite outgrowth in NG108-15 cells," Neuroendocrinology, vol. 75, no. 1, pp. 70-81, 2002.

[129] P. Kilian, S. Campbell, L. Bilodeau et al., “Angiotensin II type 2 receptor stimulation increases the rate of NG108-15 cell migration via actin depolymerization," Endocrinology, vol. 149, no. 6, pp. 2923-2933, 2008.

[130] S. Tsuzuki, S. Eguchi, and T. Inagami, "Inhibition of cell proliferation and activation of protein tyrosine phosphatase mediated by angiotensin II type $2\left(\mathrm{AT}_{2}\right)$ receptor in $\mathrm{R} 3 \mathrm{~T} 3$ cells," Biochemical and Biophysical Research Communications, vol. 228, no. 3, pp. 825-830, 1996.

[131] S. Tsuzuki, T. Matoba, S. Eguchi, and T. Inagami, “Angiotensin II type 2 receptor inhibits cell proliferation and activates tyrosine phosphatase," Hypertension, vol. 28, no. 5, pp. 916-918, 1996.

[132] M. Horiuchi, W. Hayashida, T. Kambe, T. Yamada, and V. J. Dzau, "Angiotensin type 2 receptor dephosphorylates Bcl-2 by activating mitogen-activated protein kinase phosphatase1 and induces apoptosis," The Journal of Biological Chemistry, vol. 272, no. 30, pp. 19022-19026, 1997.

[133] S. P. Bottari, I. N. King, S. Reichlin, I. Dahlstroem, N. Lydon, and M. de Gasparo, "The angiotensin $\mathrm{AT}_{2}$ receptor stimulates protein tyrosine phosphatase activity and mediates inhibition of particulate guanylate cyclase," Biochemical and Biophysical Research Communications, vol. 183, no. 1, pp. 206-211, 1992.

[134] K. Bedecs, N. Elbaz, M. Sutren et al., “Angiotensin II type 2 receptors mediate inhibition of mitogen-activated protein kinase cascade and functional activation of SHP-1 tyrosine phosphatase," Biochemical Journal, vol. 325, no. 2, pp. 449454, 1997.

[135] M.-O. Guimond and N. Gallo-Payet, "How does angiotensin AT2 receptor activation help neuronal differentiation and improve neuronal pathological situations?" Frontiers in Endocrinology, vol. 3, 2012.

[136] X. C. Huang, E. M. Richards, and C. Sumners, "Mitogenactivated protein kinases in rat brain neuronal cultures are activated by angiotensin II type 1 receptors and inhibited by angiotensin II type 2 receptors," The Journal of Biological Chemistry, vol. 271, no. 26, pp. 15635-15641, 1996.

[137] L. Gendron, J.-F. Oligny, M. D. Payet, and N. Gallo-Payet, "Cyclic AMP-independent involvement of Rap1/B-Raf in the angiotensin II AT2 receptor signaling pathway in NG108-15 cells," The Journal of Biological Chemistry, vol. 278, no. 6, pp. 3606-3614, 2003.

[138] L. Gendron, L. Laflamme, N. Rivard, C. Asselin, M. D. Payet, and N. Gallo-Payet, "Signals from the AT2 (angiotensin type 2) receptor of angiotensin II inhibit $\mathrm{p} 21^{\text {ras }}$ and activate MAPK (mitogen-activated protein kinase) to induce morphological neuronal differentiation in NG108-15 cells," Molecular Endocrinology, vol. 13, no. 9, pp. 1615-1626, 1999. 


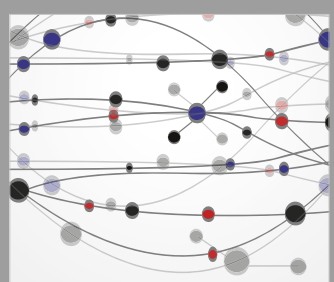

The Scientific World Journal
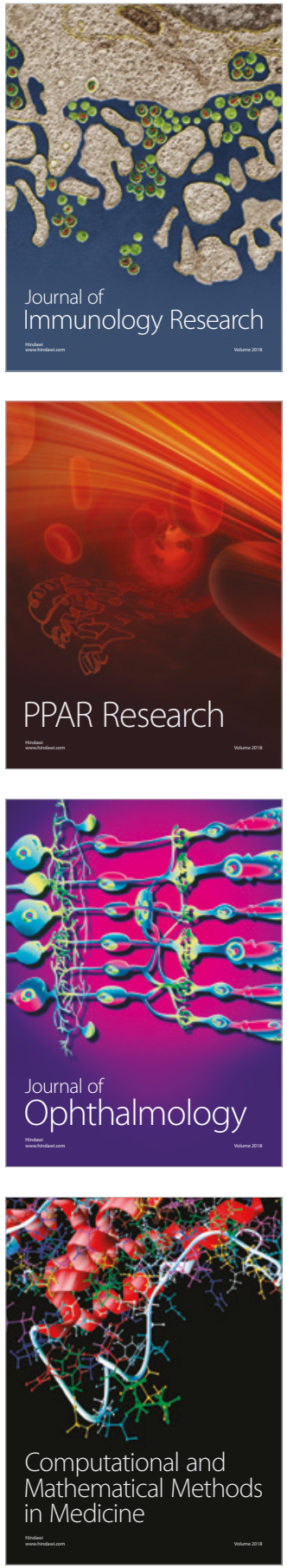

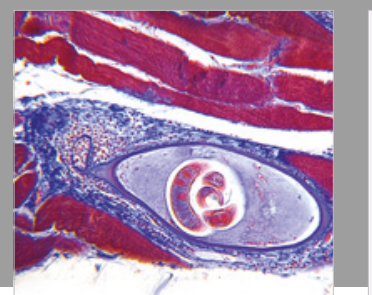

Gastroenterology Research and Practice

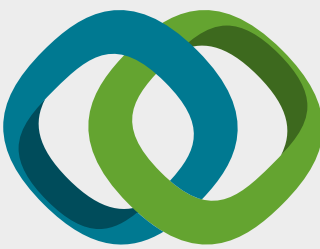

\section{Hindawi}

Submit your manuscripts at

www.hindawi.com
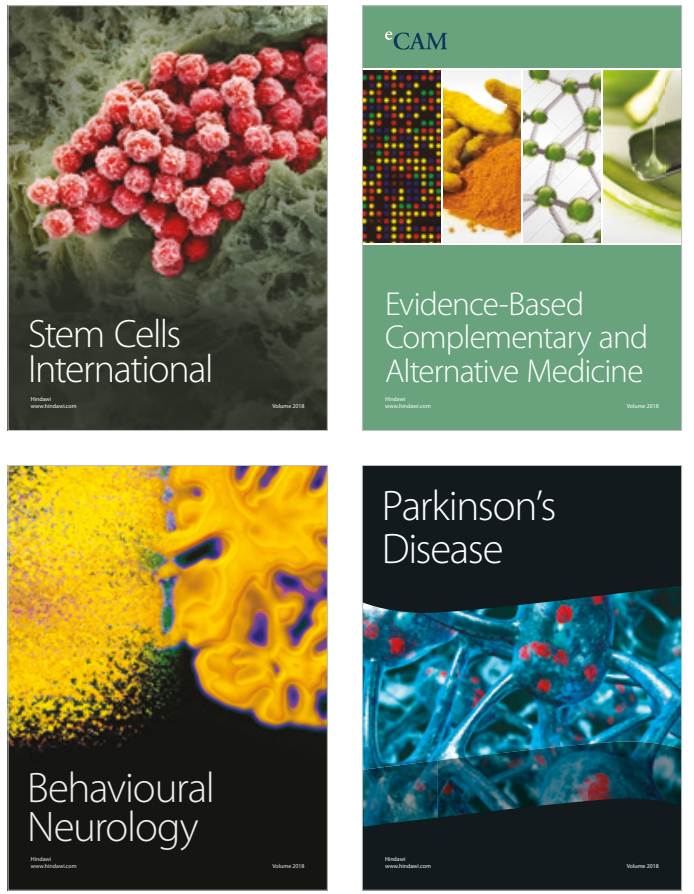

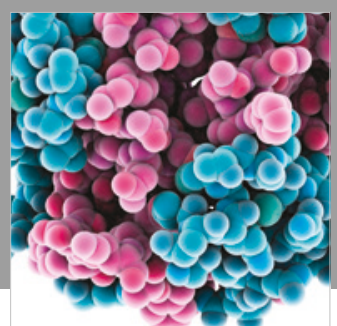

ournal of

Diabetes Research

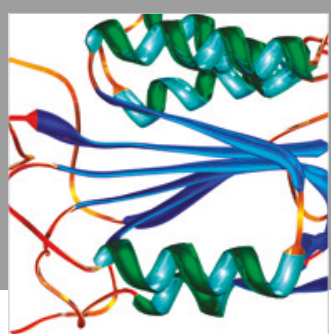

Disease Markers
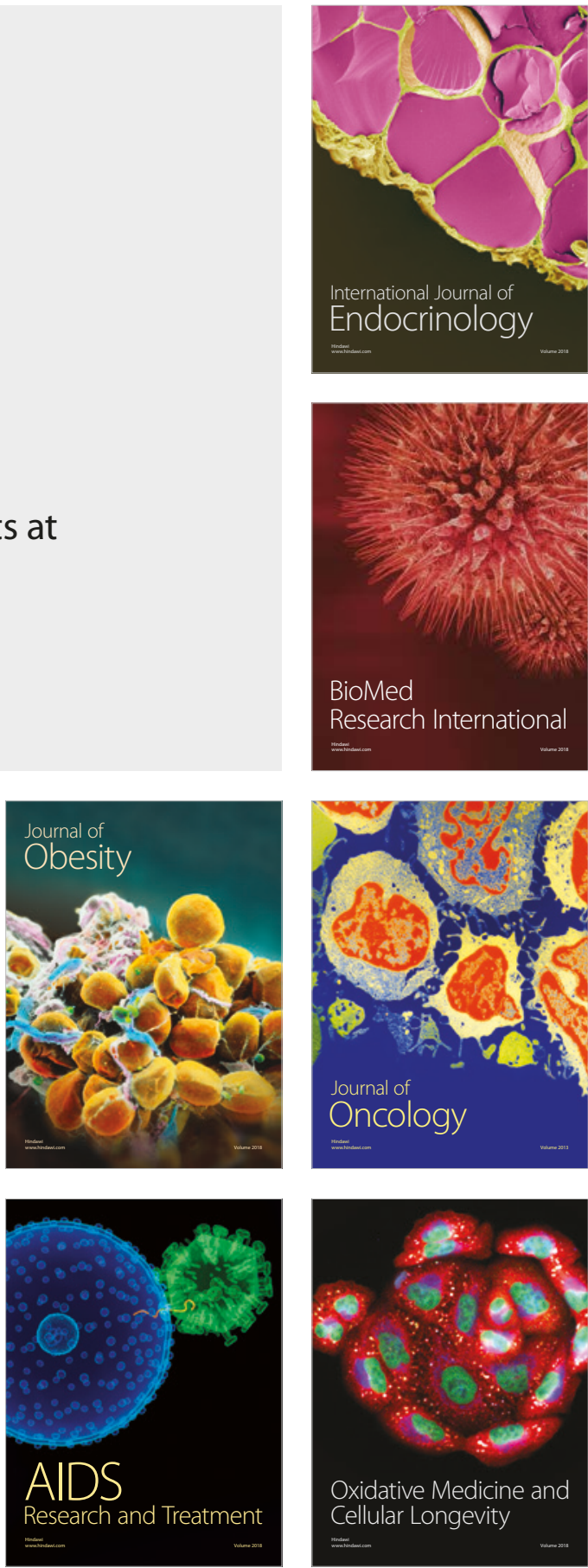